\title{
Confiabilidad de las pruebas comerciales para la detección del virus de la Hepatitis $\mathbf{C}$
}

\author{
Reliability of commercial tests for Hepatitis C virus
}

\section{Sr. Editor:}

Utilizando ensayos serológicos disponibles en el mercado, se trató de determinar la prevalencia de diversas infecciones (Hepatitis A, B y C; Treponema pallidum, Toxoplasma gondii, Cryptococcus $e$ Histoplasma) en una población de personas con el virus de inmunodeficiencia humana (VIH) en Lima, Perú. Se hicieron evidentes inconsistencias significativas en la reproducibilidad de los resultados en algunos de estos ensayos. Nosotros encontramos discrepancias entre los resultados de nuestro grupo en un laboratorio de investigación y los resultados obtenidos en un laboratorio comercial (acreditado por el Colegio Americano de Patólogos). A continuación, destacamos las pruebas para la detección del virus hepatitis $\mathrm{C}$ (VHC) como ejemplo.

De 443 muestras de suero analizadas en el laboratorio de investigación utilizando el kit Bioelisa VHC $4.0 \AA$, 58(13\%) fueron positivos, un hallazgo inusualmente alto ante un reporte previo de prevalencia del VHC en el Perú de alrededor de 1\%; sin embargo, la prevalencia puede ser mayor entre personas portadoras del VIH (1).

Se remitieron 30 muestras a un laboratorio comercial para la confirmación con su propio kit de detección de IgG/IgM del VHC (Wantai Hepatitis C Virus Diagnostics $\mathrm{AiD}^{\mathrm{TM}}$ anti-VHC ELISA ${ }^{\text {Plus, }}$,
Beijing). Los resultados fueron impresionantemente incompatibles: de 10 muestras que resultaron negativas en el laboratorio de investigación, 1 (10\%) resultó positiva en el laboratorio comercial. De 20 muestras positivas en el laboratorio de investigación, 17 (85\%) dieron un resultado negativo discordante con el laboratorio comercial; esta frecuencia de discrepancia fue mayor que el esperado por el azar $(p<0,0001)$.

Posteriormente, otro grupo de 88 muestras (30 negativas y 58 positivas por el laboratorio de investigación) fueron enviados en ciego para su análisis en el laboratorio comercial, incluyendo 21 muestras que fueron procesadas allí anteriormente. De estas últimas 21 muestras, 4 fueron positivas inicialmente en el laboratorio comercial. Para nuestro desconcierto, las 88 muestras fueron negativas, incluyendo las 4 muestras que habían sido positivas en la ejecución inicial; resultados discordantes de las muestras analizadas dos veces, se produjeron con más frecuencia de lo que se habría esperado por azar $(p<0,0001)$. Se informó al laboratorio comercial de estas discrepancias; ellos repitieron el ensayo en todas las 88 muestras, se reportó 7 (8\%) resultados positivos, incluyendo las 4 muestras que habían sido positivas en un proceso inicial.

Los ensayos utilizados en cada laboratorio fueron técnicas de inmunoabsorción ligado a enzimas (ELISA)

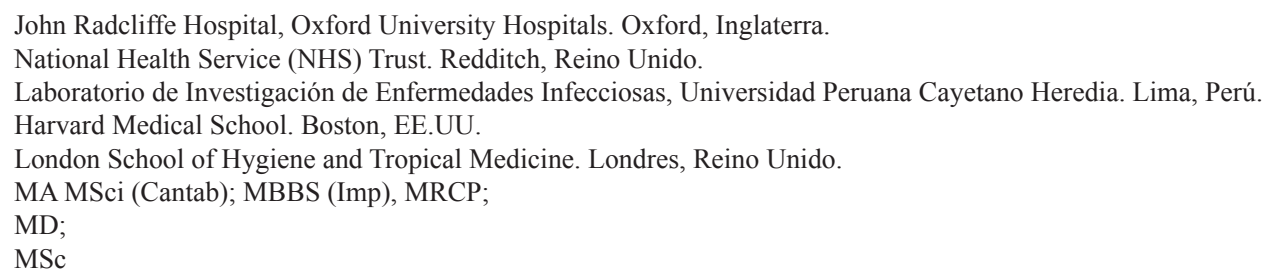


de tercera generación para la detección cualitativa de anticuerpos al VHC. Esta clase de técnicas, en general, han mostrado alta sensibilidad y especificidad, aunque no hallamos estudios previos sobre el ensayo Biokit (2).

Sin embargo, en algunos lugares, las pruebas de enzimoinmunoanálisis (EIA) de tercera generación se pueden asociar a una alta tasa de falsos positivos. En Uganda, 76 de 1000 personas tenían un EIA positivo de anticuerpos del VHC, pero ninguno RNA detectable; los resultados positivos al EIA se asociaron significativamente a un anticuerpo para Schistosoma, lo cual sugiere reactividad cruzada (3).

Los resultados falsos negativos son también posibles. En personas inmunocomprometidas, incluyendo aquellos coinfectados con el VIH, pacientes en diálisis y equipos de trasplante; la infección por VHC se puede presentar no obstante tener anticuerpos no detectables por los ensayos (4). Contrario a ello en algunos pacientes con infección aguda no se evidencia el desarrollo de anticuerpos para el VHC.

Los métodos de detección utilizados en nuestro estudio han sido validados y la mayoría es el estándar de oro para la detección de cada patógeno. Para

Tabla 1. Sensibilidad, especificidad y coeficientes de variabilidad de ensayos utilizados en nuestro trabajo.

\begin{tabular}{|c|c|c|c|c|c|c|}
\hline Prueba & Sensibilidad & Especificidad & $\begin{array}{l}\text { variabilidad } \\
\text { intra-ensayo }\end{array}$ & $\begin{array}{c}\text { variabilidad } \\
\text { inter-ens ayo }\end{array}$ & Estándar de oro & $\begin{array}{l}\text { Verificación } \\
\text { externa }\end{array}$ \\
\hline $\begin{array}{l}\text { Bioe lisa HAV (virus de la } \\
\text { hepatitis A, combinado IgG-IgM) }\end{array}$ & $99,8 \%(5)$ & $99,5 \%(5)$ & $3,5 \%(5)$ & $2,6 \%(5)$ & Solo IgM & No \\
\hline $\begin{array}{l}\text { Bioelisa HBs Ag Colour } \\
\text { (antigeno de superficie de la } \\
\text { hepatitis B) }\end{array}$ & $100 \%(5)$ & $99,5 \%(5)$ & $2,5 \%(5)$ & $1,5 \%(5)$ & Sí, como tamizaje inicial & No \\
\hline $\begin{array}{l}\text { Bioelisa } \mathbf{H C V} \text { (virus de la } \\
\text { hepatitis } C \text { ) }\end{array}$ & $100 \%(5)$ & $99 \%(5)$ & $6,9 \%(5)$ & $4,6 \%(5)$ & $\begin{array}{l}\text { Sí, en conjunto con el } \\
\text { ARN del VHC }\end{array}$ & No \\
\hline $\begin{array}{l}\text { Syphagen TPHA* (Treponema } \\
\text { pallidum ensayo hemo - } \\
\text { aglutinación para la sifilis) }\end{array}$ & $99-100 \%(5)$ & $99 \%(5)$ & - & - & $\begin{array}{l}\text { Sí, en conjunción con la } \\
\text { prueba serológica no } \\
\text { treponémica }\end{array}$ & $\mathrm{Si}$ \\
\hline $\begin{array}{l}\text { Bioelis a Toxo IgG** } \\
\text { (Toxoplasma gondii) }\end{array}$ & $100 \%(5)$ & $98,6 \%(5)$ & $2,7 \%(5)$ & $4,9 \%(5)$ & $\begin{array}{l}\text { No. El estándar de oro es } \\
\text { el test de Sabin - Feldman, } \\
\text { no disponible } \\
\text { rutinariamente }\end{array}$ & No \\
\hline $\begin{array}{l}\text { Latex-Cryptococcus Antigen } \\
\text { Detection System***}\end{array}$ & $93-100 \%(6)$ & $93-100 \%(6)$ & - & - & $\begin{array}{l}\text { El diagnóstico en conjunto } \\
\text { es con el análisis del LCR, } \\
\text { la tintaChina. El suero es } \\
\text { menos preciso que LCRen } \\
\text { pacientes sin SIDA. }\end{array}$ & No \\
\hline $\begin{array}{l}\text { LA-His toplas ma Antibody } \\
\text { System (aglutinación enlátex) }\end{array}$ & $62 \%(6)$ & $97 \%(6)$ & - & - & $\begin{array}{l}\text { El diagnóstico en conjunto } \\
\text { es con el cultivo, tinción y } \\
\text { la detección del antígeno }\end{array}$ & No \\
\hline $\begin{array}{l}\text { Aid }^{T M} \text { anti-HCV ELISA } \\
\text { (WLUS }^{\text {PLai Hepatitis C C Virus }} \\
\text { Diagnostics) }\end{array}$ & $100 \%(7)$ & $99,96 \%(7)$ & - & - & $\begin{array}{l}\text { Sí, en conjunto con el } \\
\text { ARN del VHC }\end{array}$ & $\mathrm{Si}$ \\
\hline
\end{tabular}

Cada ensayo de calidad ha sido controlado internamente por la empresa de la producción.

* Se recomienda que el uso de una sola prueba serológica es insuficiente para el diagnóstico ya que cada prueba tiene limitaciones de diagnóstico, se debe utilizar una prueba no treponémica para el tamizaje seguido de una prueba treponémica específica para confirmar la infección. Se utilizó una prueba treponémica.

** Las pruebas de ELISA comerciales han surgido para convertirse en elestándar más practicable para el diagnóstico, sin embargo, el rendimiento de estas pruebas varía. Al comparar 6 ensayos diferentes ( $\sin$ incluir el ensay o Biokit utilizado en nuestro trabajo) la sensibilidad fue $93,3 \%-100 \%$ y la especificidad fue $77,5 \%-99,1 \%$. La reproducibilidad de los resultados no se investigó (8).

***En una comparación de 5 ensayos para la detección criptococócica (4 aglutinaciones en latex y 1 ELISA), el ensayo de aglutinación Immy Látex para antígenos polisacáridos de Cryptococcus neoformans estaba entre los más exactos cuando se investiga el suero (sensibilidad $97 \%$, especificidad $93 \%$ ) y el líquido cefalorraquídeo (sensibilidad $93 \%$, especificidad 93\%). La reproducibilidad de los resultados no se investigó (9). 
determinar la existencia de reportes anteriores sobre la variación significativa en la precisión entre los ensayos comerciales individuales, una revisión de la literatura se realizó utilizando Medline y Uptodate (Tabla 1).

Los datos reportados plantean dudas acerca de la validez de los resultados en los que se evidencia inconsistencias, también plantea interrogantes más generales acerca de los métodos de laboratorio utilizados para la detección de la VHC y otros patógenos.

- ¿Son diferentes las características de rendimiento de las pruebas serológicas en una población de inmunocomprometidos? En la investigación de una población potencialmente inmunocomprometida como este caso, personas con $\mathrm{VIH}$, existe el riesgo que las pruebas que dependen de una respuesta inmune activa (por ejemplo, la detección de anticuerpos) sean menos sensibles cuando se usa en una población inmunocompetente.

- ¿Se pueden obtener diferencias sustanciales en los resultados de ensayos de diferentes fabricantes? Hay que cuestionar cuidadosamente la validez de los ensayos utilizados en cuanto a su precisión y reproducibilidad. A pesar de la garantía interna de calidad, ninguno de los ensayos fue validado por una organización de estándares nacionales o internacionales de calidad independiente, como la Food and Drug Administration (FDA) de los Estados Unidos con excepción de la prueba Syphagen TPHA para la sífilis. Para algunas pruebas utilizadas en menor escala a nivel internacional (por ejemplo, ensayos de diagnóstico para Cryptococcuse Histoplasma), puede haber barreras financieras para solicitar la validación acordada internacionalmente. Sin embargo, la supervisión de la calidad de los ensayos es crucial. Un estudio destacó la variabilidad entre ensayos comerciales para el VHC y sugirió la combinación de ensayos en paralelo para aumentar la sensibilidad (10).

- ¿Se pueden obtener resultados fiables y reproducibles a partir de ensayos serológicos realizados en un laboratorio de investigación, incluso cuando se sigue cuidadosamente las instrucciones de un kit disponible en el mercado? Cada prueba es ejecutada por un humano y deja abierta la posibilidad de error inducido por el operador. Sin embargo, suponiendo que el operador lleva a cabo la prueba según las instrucciones del fabricante en un entorno de laboratorio controlado y completando los controles de calidad al mismo tiempo, es de esperar que no causara discrepancias en los resultados. El grado de variabilidad "normal" debe ser definido para cada ensayo.

- ¿Qué pasa con los resultados obtenidos de un laboratorio comercial acreditado? Los mismos problemas se aplican aquí como en laboratorios de investigación más pequeños. El control de calidad debe garantizarse no sólo de la prueba de diagnóstico en sí, sino también del laboratorio individual, sus prácticas y el personal.

Dado el potencial de variabilidad inter e intra ensayo, los datos de los estudios de investigación individuales pueden requerir confirmación en otros entornos. Esto refuerza la idea de que las pruebas de laboratorio no existen solo para el diagnóstico o el manejo direccionado de un paciente. El contexto clínico debe ser considerado, dado que las pruebas de laboratorio, incluso las certificadas, pueden generar ambigüedad e irreproducibilidad.

\section{Robert H. Shaw 1,2,a, Krishna P. Reddy ${ }^{3,4, b}$, Jorge Coronel $^{3, c}$, David A. J. Moore ${ }^{3,5}$}

\section{Fuentes de Financiamiento y declaración de conflictos de interés:}

El proyecto recibió el apoyo de un Premio Académico para la Investigación Clínica del Centro Internacional Fogarty y la beca T32 AI007433 de los Institutos Nacionales de Salud de los EEUU, y un Premio del Wellcome Trust (078067/Z/05). El contenido es responsabilidad exclusiva de los autores y no representa necesariamente las opiniones oficiales de las entidades señaladas. Todos los autores declaran que no tienen ningún conflicto de intereses en relación con este artículo.

\section{Correspondencia:}

Robert H. Shaw.

John Radcliffe Hospital, Oxford University Hospitals NHS Trust, UK. robertshaw@doctors.org.uk,

Teléfono: 44 (0) 7771794927 


\section{REFERENCIAS BIBLIOGRÁFICAS}

1. Dávalos M. Epidemiology of Hepatitis C Virus in Peru and LatinAmerica. Rev Gastroenterol Peru. 2009; 29(4):347-54.

2. Colin C, Lanoir D, Touzet S, et al..Sensitivity and specificity of third-generation hepatitis $\mathrm{C}$ virus antibody detection assays: an analysis of the literature. J Viral Hepat. 2001; 2:87-95.

3. Mullis CE, Laeyendecker O, Reynolds SJ, et al. High frequency of false-positive hepatitis $\mathrm{C}$ virus enzymelinked immunosorbent assay in Rakai, Uganda. Clin Infect Dis. 2013; 57(12):1747-50.

4. Lau JY, Davis GL, Brunson ME, et al. Hepatitis $\mathrm{C}$ virus infection in kidney transplant recipients. Hepatology. 1993;18(5):1027-31.

5. Biokit S.A. BioELISA Instruments: Test manuals; Lliçà d'Amunt, Barcelona: BIOKIT.

6. IMMY. Immunodiffusion kits, reagents, and plates: Test manuals; Norman, OK: IMMY.
7. Beijing Wantai Biological Pharmacy Enterprise. Wantai HTLV Ab ELISA: Test manuals. Beijing: Beijing Wantai Biological Pharmacy Enterprise.

8. Wilson M, Remington JS, Clavet C, Varney G, Press C, Ware D. Evaluation of six commercial kits for detection of human immunoglobulin $\mathrm{M}$ antibodies to Toxoplasma gondii. J Clin Microbiol. 1997; 35(12):3112-3115.

9. Tanner DC, Weinstein MP, Fedorciw B, Joho KL, Thorpe JJ, Reller L. Comparison of commercial kits for detection of Cryptococcal antigen. J Clin Microbiol. 1994; 32(7):1680-1684.

10. Zhang K, Wang L, Sun Y, et al. Improving the safety of blood transfusion by using a combination of two screening assays for hepatitis $\mathrm{C}$ virus. Transfus Med. 2014; 24(5):297-304. doi: 10.1111/tme.12152

Recibido: 05/10/2017 